\title{
AN ADJUSTABLE THICKNESS Li/Be TARGET FOR FRAGMENTATION OF 3-kW HEAVY ION BEAMS
}

\author{
J.A. Nolen ${ }^{1}$, C.B. Reed ${ }^{2}$, A. Hassanein ${ }^{3}$, V. J. Novick ${ }^{2}$, P. Plotkin ${ }^{2}$, and J.R. Specht ${ }^{1}$ \\ ${ }^{1}$ Physics Division, ${ }^{2}$ Technology Development Division, ${ }^{3}$ Energy Technology Division \\ Argonne National Laboratory, Argonne, IL 60439, USA \\ D.J. Morrissey, J.H. Ottarson, and B.M. Sherrill \\ National Superconducting Cyclotron Lab., Michigan State U., East Lansing, MI 48824, USA
}

\begin{abstract}
As a first step towards developing liquid lithium target technology for a future high-power nuclear physics fragmentation facility, an adjustable thickness $\mathrm{Li} / \mathrm{Be}$ hybrid target is being constructed for use at the NSCL. This target will use beryllium windows with flowing lithium. The lithium serves as a part of the target as well as the coolant. Up to $1 \mathrm{~kW}$ of beam power is dissipated in the target and is carried away by the recirculating liquid lithium loop. It is designed for high power beams in the mass range from oxygen to calcium. Tapered beryllium windows combined with a uniform thickness lithium channel gives an overall target thickness ranging from $0.7 \mathrm{~g} / \mathrm{cm}^{2}$ to $3 \mathrm{~g} / \mathrm{cm}^{2}$, which is adjusted by moving the target vertically. The target system design is complete and is described in this paper.
\end{abstract}

PACS codes: $25.70 . \mathrm{Mn}, 29.25 . \mathrm{Rm}$

Keywords: Radioactive beam, heavy ion fragmentation, high power target, liquid lithium

Corresponding author: Jerry Nolen, e-mail: Nolen@ANL.GOV. 


\section{Introduction}

The need for a thick windowless liquid lithium target for use with high intensity uranium beams at next-generation radioactive beam facilities has been discussed $[1,2]$. For lighter heavy ions at such high energy fragmentation facilities require thicker targets, in the $5-10 \mathrm{~g} / \mathrm{cm}^{2}$ range, which corresponds to $10-20 \mathrm{~cm}$ in thickness if pure lithium is used. Since the density of beryllium is about 4 times that of lithium, a hybrid target using both lithium and beryllium was proposed [2]. A first-generation target of this type for use with beam power of up to $3 \mathrm{~kW}$ is currently under construction for use with beams from oxygen to calcium at the NSCL A1900 fragment separator [3]. A schematic layout of this target concept is shown in Fig. 1. The design of this target, which covers a thickness range from 0.7 to $3 \mathrm{~g} / \mathrm{cm}^{2}$, is described in this paper.

\section{Concept for the hybrid target}

At high energies there is relatively little influence of the target material on the distribution of produced fragments. In this case, low- $Z$ target materials are preferred since the overall production rate is larger. Beryllium and graphite have been used extensively at existing fragmentation facilities. Lithium is also an appropriate choice for target material and, as discussed previously, is also an excellent cooling medium. A combination of beryllium and liquid lithium can be used to keep the total linear target thickness down. At the NSCL after the recently completed Coupled Cyclotron Upgrade [3], the most powerful beams are in the mass range between oxygen and calcium where beam power up to $3 \mathrm{~kW}$ is possible. For these beams a target thickness over the range from 0.7 to $3 \mathrm{~g} / \mathrm{cm}^{2}$ is a good match to the acceptance of the A1900. The hybrid-target spool piece designed to cover this thickness range is shown schematically in Fig. 2. 


\section{Thermal calculations}

Three-dimensional thermal calculations of the temperature profiles in the entrance and exit regions of the target have been carried out using the HEIGHTS simulation program [4]. The results of the simulations done for a ${ }^{48} \mathrm{Ca}$ beam at $160 \mathrm{MeV} / \mathrm{u}$ and 0.5 particle microampres at the thin end of the target (1-mm beryllium windows and 5-mm lithium thickness) are shown in Fig.

3. Corresponding results for an ${ }^{16} \mathrm{O}$ beam at $200 \mathrm{MeV} / \mathrm{u}$ and 1.0 particle microamperes at the thick end (7-mm beryllium windows and 5-mm lithium) are shown in Fig. 4. For these calculations a heat transfer coefficient of $20 \mathrm{~W} / \mathrm{cm}^{2}-\mathrm{K}$ was used for the liquid lithium flowing at a velocity of $5 \mathrm{~m} / \mathrm{s}$.

\section{Pressure/flow requirements and pump design}

The approximately $1-\mathrm{kW}$ power dissipation in the target implies that only a relatively low volume flow rate, $\sim 4 \mathrm{~m} / \mathrm{s}$, is required to keep the peak temperature rise in the lithium to about $100{ }^{\circ} \mathrm{C}$. With a channel cross section of $5 \mathrm{~mm}$ by $10 \mathrm{~mm}$ in the target spool piece, the pressure drop across the target is only $\sim 3000$ Pascals. The liquid-lithium pump design and the pipe sizing of the lithium loop were chosen to be compatible with this target flow rate and pressure drop.

A DC, permanent magnet Lorenz-force type of pump was chosen for this application. This type and other liquid metal pumps are reviewed in a NASA report [5]. Because of the operating temperature of $\sim 200{ }^{\circ} \mathrm{C}, \mathrm{Sm}_{2} \mathrm{Co}_{17}$ permanent magnet material is being used for the pump. This material is also $\sim 1000$ times more radiation resistant than $\mathrm{NdFeB}$ permanent magnet materials $[6,7]$. A prototype pump has been built and tested using a $\mathrm{Ga} / \mathrm{In}$ alloy that is liquid at room temperature. A schematic of the present pump design is shown in Fig. 5. It is a smaller and simpler version of a liquid gallium pump developed by Smither [8]. 


\section{Mechanical layout}

The target assembly, liquid-lithium loop, lithium pump, and associated heaters and temperature monitors comprise an assembly that mounts on the top flange of the target vacuum chamber of the NSCL A1900 fragment separator and is compatible with the standard target ladder. The operating temperature of the liquid-lithium loop is $200{ }^{\circ} \mathrm{C}$ so that the heater control system will have to adjust the heater power as required by the amount of beam power being dissipated in the target. A mechanical assembly drawing of the overall target system is shown in Fig. 6. A detailed system design description is given in [9].

\section{Safety issues and procedures}

One of the goals of this project is to develop procedures for the safe operation of liquidlithium target systems at a radioactive beam facility. The general safety issues associated with liquid alkalis were discussed at a previous conference [1]. Such procedures have been developed and used in fusion research programs and liquid-metal cooled reactors. The present target uses a closed lithium loop, which is an intermediate step towards the operation of a windowless target at a nuclear physics accelerator facility. However, to provide an additional measure of isolation of the liquid lithium from the laboratory environment, the present design incorporates a secondary containment vessel as shown in Fig. 6, as well as, a pressure relief valve for the argon cover gas above the lithium in the closed loop.

\section{Construction and testing schedule}

The design of this prototype target is complete and fabrication is in progress. The DC pump has been constructed and the beryllium spool piece has been procured. The present plan is to complete fabrication of the target system at the NSCL in the fall of this year, and to assemble and 
test it, without beam, at Argonne soon thereafter. It should be ready for commissioning at the NSCL A1900 in 2003.

\section{Acknowledgements}

Work supported by the U. S. Department of Energy under contract W-31-109-ENG-38.

\section{References}

1. J.A. Nolen, C.B. Reed, A. Hassanein, and I.C. Gomes, Nucl. Phys. A701 (2002) 312c322c.

2. J.A. Nolen, et al., abstract \#78, this conference.

3. D.J. Morrissey, abstract \#70, this conference

4. A. Hassanein and I. Konkashbaev, J. Nucl. Mater. 273 (1999) 326.

5. J.P. Verkamp and R.G. Rhudy, "Electromagnetic Alkali Metal Pump Research Program," NASA Contractor Report CR-380, Feb. 1966.

6. A.F. Zeller and J.A. Nolen, $9^{\text {th }}$ Int. Workshop on Permanent Magnets, Bad Sodem, FRG, (1987) 159.

7. O.-P. Kähkönen, et al., Phys. Rev. B49 (1994) 6052-6057.

8. R.K. Smither, "Summary of the Operating Characteristics of the ANL Liquid Metal Pump after its Latest Modification, APS Technical Memo: AGP-III-M, September 20, 1995.

9. "System Design Description for the ANL/MSU Li/Be Target Loop," ANL/TD document G0586-0003-SA, July 2002. 


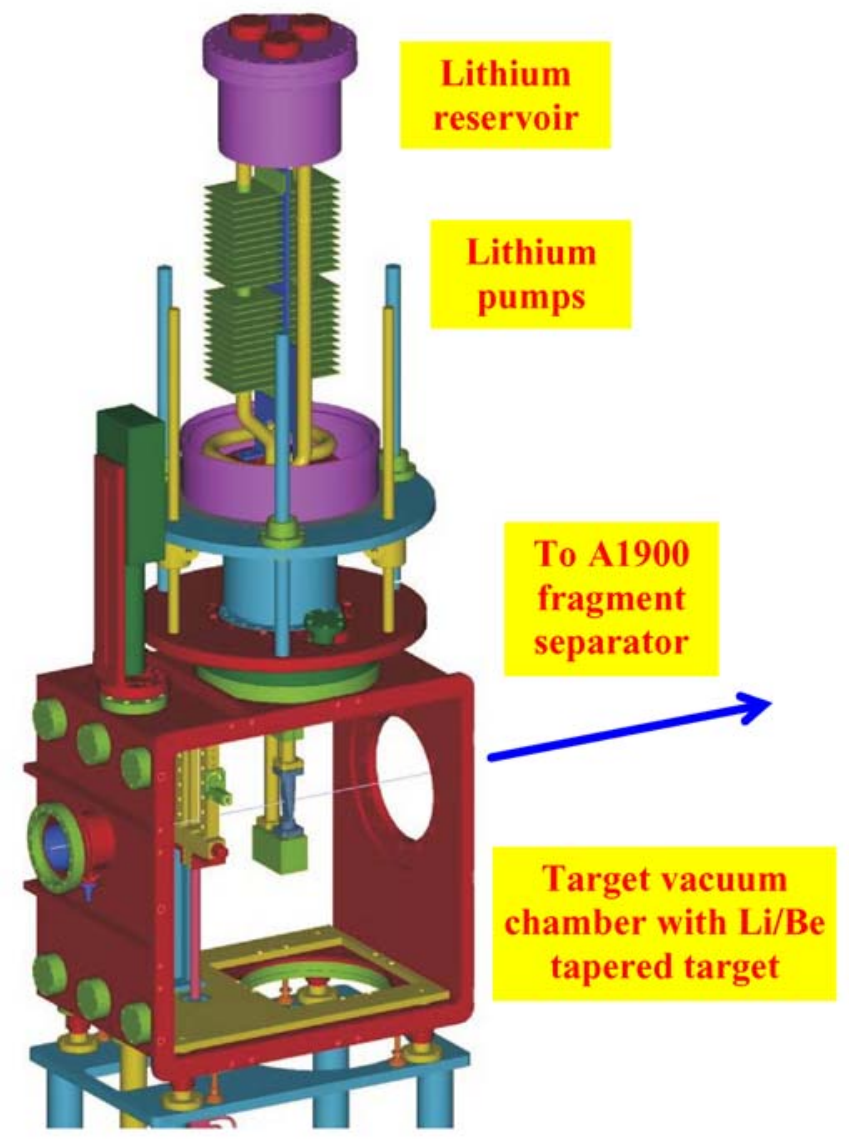

Fig. 1. A schematic view of the target chamber at the NSCL A1900 fragment separator. The chamber is designed to accommodate the liquid lithium loop from above and a standard target ladder from below. The containment vessel is removed in this view.

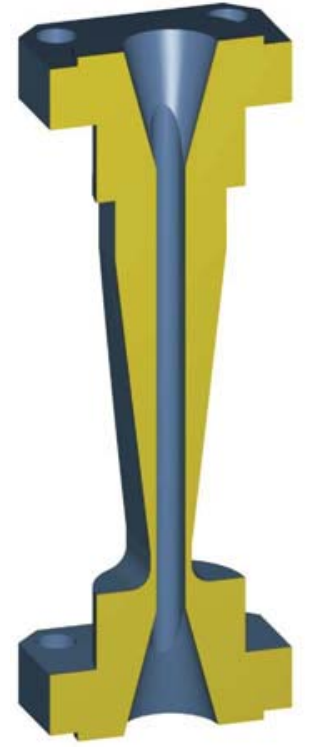

Fig. 2. A cutaway view of the beryllium target spool piece for the hybrid target. The beryllium entrance and exit windows vary from 1-mm thick at one end to 7-mm thick at the other. Lithium flows between the windows and is $5 \mathrm{~mm}$ thick. The overall target varies from $0.7 \mathrm{~g} / \mathrm{cm}^{2}$ to 3 $\mathrm{g} / \mathrm{cm}^{2}$. 


\section{Temperature on $\mathbf{x}-\mathbf{z}$ plane at $\mathbf{y}=\mathbf{0 ~} \mathrm{mm}$ on the front plate}

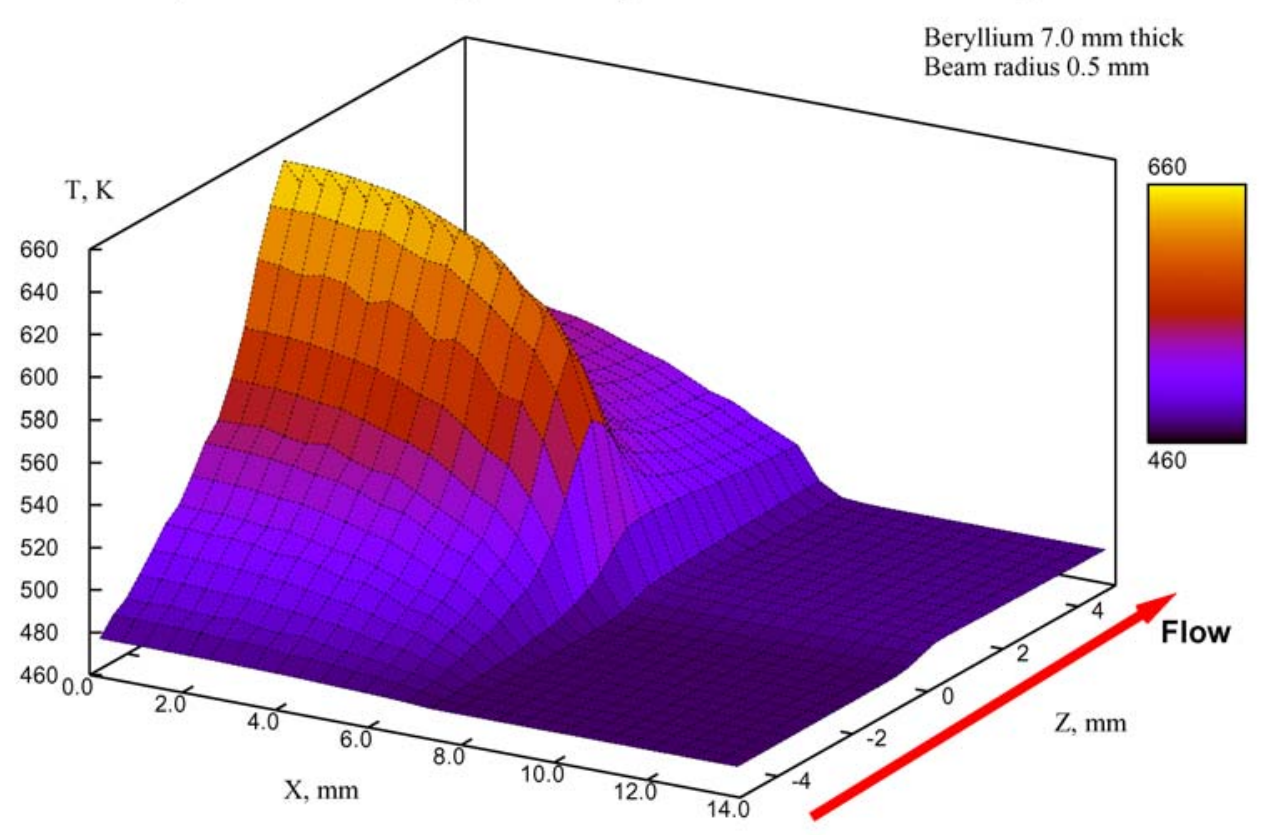

Fig. 3. Three-dimensional thermal calculation of the temperature distribution in the beryllium window and flowing lithium for the case of a $200 \mathrm{MeV} / \mathrm{u}{ }^{16} \mathrm{O}$ beam at an intensity of 1 particle microampere. The peak temperature is at the outside surface of the beryllium and is $660 \mathrm{~K}$.

\section{Temperature on $\mathbf{x}-\mathbf{z}$ plane at $\mathbf{y}=\mathbf{0 ~} \mathrm{mm}$ on the front plate}

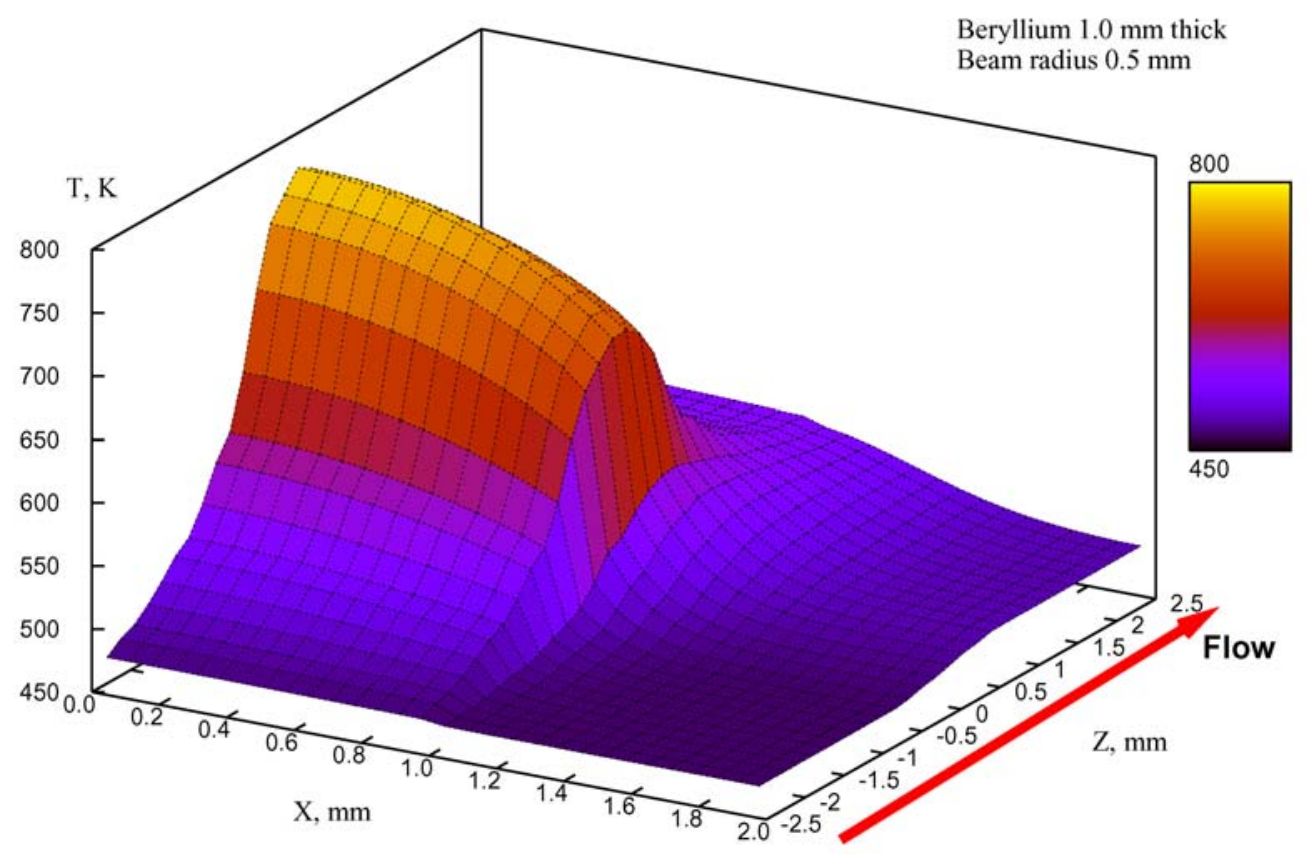

Fig. 4. Three-dimensional thermal calculation of the temperature distribution in the beryllium window and flowing lithium for the case of a $160 \mathrm{MeV} / \mathrm{u}{ }^{48} \mathrm{Ca}$ beam at an intensity of 0.5 particle microampere. The peak temperature is at the outside surface of the beryllium and is 800 $\mathrm{K}$. 


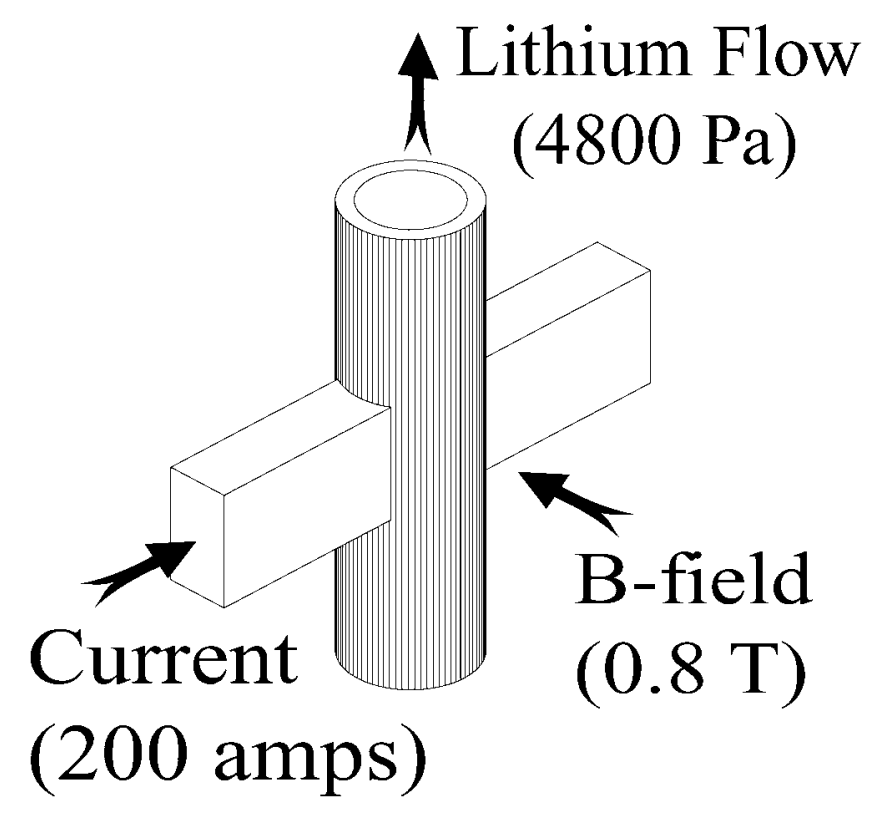

Fig. 5. Schematic diagram of the permanent-magnet, liquid-lithium pump. The pump is designed to deliver a volume flow rate of $200 \mathrm{~cm}^{3} / \mathrm{s}$ at the pressure, current, and magnetic field indicated. With these parameters and the piping as designed, the flow velocity through the target spool piece is $4 \mathrm{~m} / \mathrm{s}$ and the pump voltage is $24 \mathrm{mV}$. The no-flow voltage is $10 \mathrm{mV}$. The stainless steel tube through the pump is $12.7 \mathrm{~mm}$ outside diameter and the wall thickness is 1.6 $\mathrm{mm}$. 

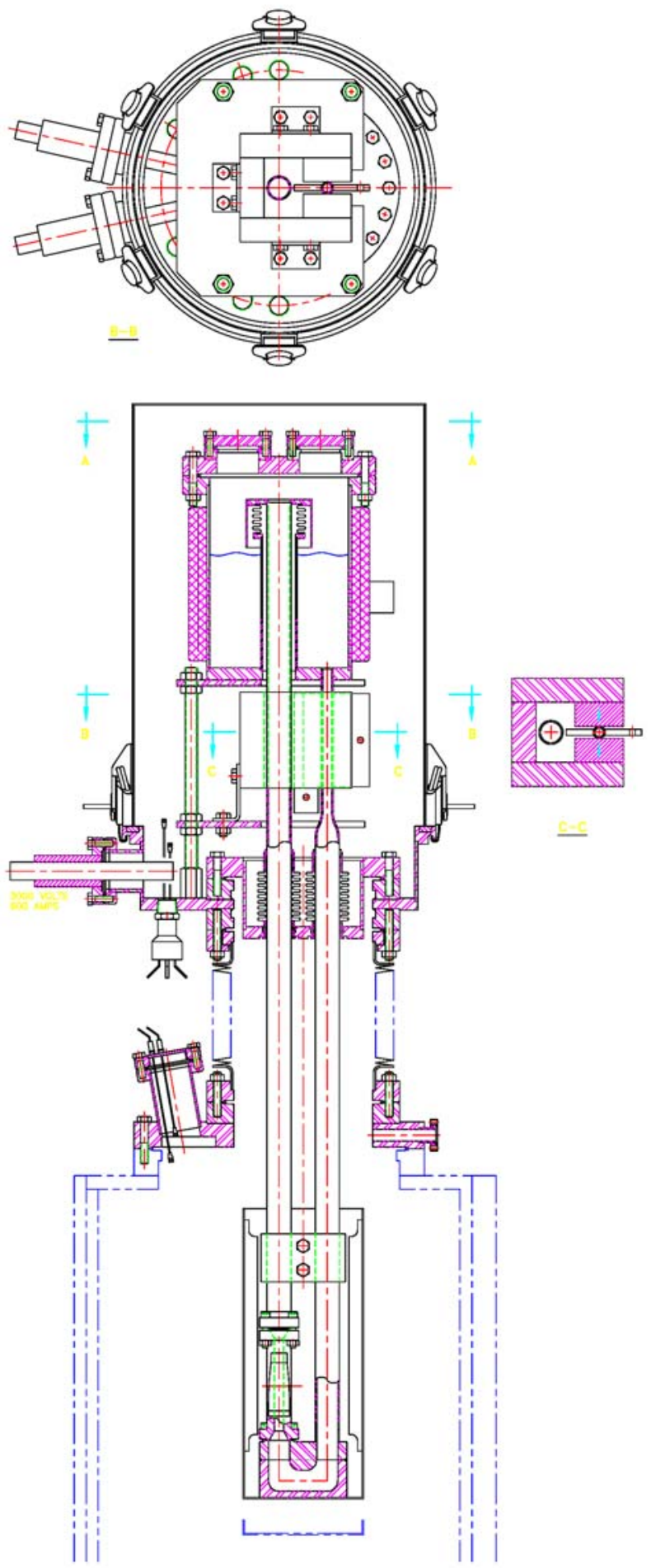

Fig. 6. Drawing of the mechanical layout of the liquid-lithium loop. The mechanism can move vertically with respect to the beam in order to vary the target thickness or to withdraw the mechanism to make room for the standard target ladder. A section view of the permanentmagnet pump is shown to the right. 